\title{
Galactose-positive adjunct cultures prevent gas formation by Paucilactobacillus wasatchensis WDC04 in a model gas production test
}

\author{
Ireland R. Green, ${ }^{1}$ Craig J. Oberg,,${ }^{1,2} \oplus$ Jeffery R. Broadbent, ${ }^{1 *}$ Randall K. Thunell, ${ }^{1,3} \oplus$ \\ and Donald J. McMahon ${ }^{1}+$ (i) \\ ${ }^{1}$ Western Dairy Center, Department of Nutrition, Dietetics, and Food Sciences, Utah State University, Logan 84322-8700 \\ ${ }^{2}$ Microbiology Department, Weber State University, Ogden, UT 84408-2506 \\ ${ }^{3}$ Vivolac Culture Corporation, Greenfield, IN 46140
}

\section{ABSTRACT}

Gas production by obligatory heterofermentative lactic acid bacteria such as Paucilactobacillus wasatchensis is a sporadic problem in Cheddar cheese and results in undesired slits and cracks in the cheese. Growth of $P a$. wasatchensis is not rapid, which makes investigations of gas production difficult to consistently execute. A primary objective of this study was to develop a model gas production test that could be used to investigate the effect of galactose and ribose utilization on gas production by $P a$. wasatchensis and determine whether galactose-fermenting adjunct cultures could prevent gas formation. Paucilactobacillus wasatchensis WDC04 was inoculated at $10^{1}$ to $10^{6} \mathrm{cfu} / \mathrm{mL}$ into carbohydrate-restricted MRS broth containing different ribose and galactose levels and incubated for up to $21 \mathrm{~d}$ at $23^{\circ} \mathrm{C}$. Gas production in the broth was detected using a Durham tube inverted on a 6 -cm-long capillary tube; cells were enumerated at 4, 8, and $12 \mathrm{~d}$; and residual galactose was also measured. Gas production was sporadic except for when $10^{5} \mathrm{cfu} / \mathrm{mL}$ of $P a$. wasatchensis WDC04 was inoculated into broth containing $0.3 \%$ ribose and $0.7 \%$ galactose. In those tubes, gas production was consistently observed after 8-d incubation, by which time galactose levels had decreased to $0.15 \%$. Co-inoculation of $P a$. wasatchensis WDC04 with as few as $10^{3} \mathrm{cfu} / \mathrm{mL}$ of a lactose-negative galactose-positive adjunct culture (Pediococcus acidilactici 23F, Lacticaseibacillus paracasei UW4, or Lactobacillus helveticus 7995) resulted in galactose depletion by d 4 and no observable gas production by d 12 . With less galactose available to the slower-growing $\mathrm{Pa}$. wasatchensis WDC04, its growth was limited to $10^{8} \mathrm{cfu} / \mathrm{mL}$ when any of the adjunct

Received March 9, 2021.

Accepted June 4, 2021.

*Current affiliation: Mascoma LLC, Lebanon, NH 03766.

†Corresponding author: Donald.McMahon@usu.edu cultures was co-inoculated, compared with $10^{9} \mathrm{cfu} / \mathrm{mL}$ when grown on its own. We concluded that galactosefermenting adjunct cultures have potential for preventing unwanted gas production in cheese by competition for resources and especially by removing the 6-carbon galactose before it can be utilized for energy by an obligatory heterofermentative lactobacilli such as $P a$. wasatchensis and produce carbon dioxide.

Key words: cheese, nonstarter lactic acid bacteria, unwanted gas production, galactose

\section{INTRODUCTION}

In bacterial ripened cheeses such as Cheddar, the lactic acid bacteria (LAB) are separated into 2 distinct groups: starter LAB, which are bacteria purposely added by the producer during the cheesemaking process, and nonstarter LAB (NSLAB), which are not intentionally added and initially are present at low cell numbers $\left(<10^{2} \mathrm{cfu} / \mathrm{g}\right)$ compared with starter LAB, which are initially at $10^{7}$ to $10^{9} \mathrm{cfu} / \mathrm{g}$ (Broadbent et al., 2003). The NSLAB enter the cheese because they either survive pasteurization or are introduced postpasteurization from the dairy plant environment and often become the predominant bacteria in Cheddar cheese by the time it is ready to be sold (Oberg et al., 2011; McMahon et al., 2014). Some NSLAB are viewed as positive or desired additions to the cheese microbiota, but others are associated with defects such as slits and cracks, off-flavors, and crystal formation in Cheddar cheese (Crow et al., 1995; Broadbent et al., 2003). The positive effects of some NSLAB on cheese quality has led to widespread use of adjunct cultures in starter LAB microbiology. These strains are used to improve cheese consistency, increase flavor intensity, provide unique flavors, inhibit other NSLAB, produce probiotic cheeses, accelerate ripening, improve aroma, and reduce bitterness (Wilkinson, 1993; Fox et al., 1998; Oberg et al., 2011). Such adjuncts are often isolated from the NSLAB populations of good-quality cheese. 
Paucilactobacillus wasatchensis, formerly designated Lactobacillus wasatchensis, is an obligatory heterofermentative NSLAB that causes late gas formation in aging Cheddar cheese (Ortakci et al., 2015b; Oberg et al., 2016). The ability of $P a$. wasatchensis to utilize galactose by the heterofermentative phosphoketolase pathway results in $\mathrm{CO}_{2}$ production when its preferential carbohydrate source, ribose, is not available (Ortakci et al., 2015a).

Traditionally, Cheddar cheese is made using Lactococcus lactis as the starter culture, with a cook temperature of about $39^{\circ} \mathrm{C}$ (Michel and Martley, 2001). Alternatively, a "short method" for producing Cheddar cheese can be used, in which the rate of lactic acid production is increased by including a thermophilic LAB, Streptococcus thermophilus, along with the L. lactis culture (Bley et al., 1985; Michel and Martley, 2001). Addition of $S$. thermophilus maintains faster acid production during and after cooking rather than the slowdown that occurs with L. lactis. Using $S$. thermophilus also provides the benefit of not being vulnerable to L. lactis bacteriophages (Michel and Martley, 2001). However, the majority of $S$. thermophilus strains do not utilize the galactose moiety of lactose but, rather, export it using an antiporter that brings fresh lactose into the cell. This results in galactose accumulating in the cheese (Hutkins and Ponne, 1991).

Tinson et al. (1982) observed that Cheddar cheese made with $L$. lactis ssp. cremoris starter and $S$. thermophilus adjunct cultures resulted in higher levels of residual galactose $(0.56 \% \mathrm{wt} / \mathrm{wt})$ and $\mathrm{CO}_{2}$ production. Ortakci et al. (2015c) added Pa. wasatchensis WDC04 to Cheddar cheese made with $S$. thermophilus as a starter culture and observed gas formation when the cheese was ripened at elevated temperature $\left(12^{\circ} \mathrm{C}\right)$.

A challenge in studying gas production by $P a$. wasatchensis is that it requires both growth to high numbers and utilization of galactose for energy production by the cell. When grown with galactose as the only carbohydrate, $P a$. wasatchensis has very limited growth (Ortakci et al., 2015a); whatever $\mathrm{CO}_{2}$ is formed is insufficient to exceed its solubility in water in a test tube, and no bubbles are observed in Durham tubes. In contrast, with ribose as the carbohydrate, $P$ a. wasatchensis grows to high numbers $\left(\sim 10^{9} \mathrm{cfu} / \mathrm{mL}\right)$ but, because it is already a 5-carbon sugar, no $\mathrm{CO}_{2}$ is produced. According to Ortakci et al. (2015a), when both ribose and galactose are present, they are co-utilized, with ribose being used for energy and galactose for other cellular needs, which also results in a lack of $\mathrm{CO}_{2}$ production. An objective of this research was to develop a gas production test (GPT) that could be used to study the conditions under which $\mathrm{Pa}$. wasatchensis produces $\mathrm{CO}_{2}$. A further objective was to then use the GPT to deter- mine whether an additional culture that would ferment galactose $\left(\mathrm{Gal}^{+}\right)$but not lactose $\left(\mathbf{L a c}^{-}\right)$would prevent gas formation by $\mathrm{Pa}$. wasatchensis.

\section{MATERIALS AND METHODS}

\section{Cultures}

Paucilactobacillus wasatchensis. Paucilactobacillus wasatchensis WDC04 was obtained from the culture collection at Weber State University (Ogden, UT), grown in lactobacilli de Man, Rogosa, and Sharpe broth (MRS; Hardy Diagnostics) supplemented with $1 \%$ ribose (wt/vol; MRS $+\mathbf{R}$; Sigma Aldrich Inc.), and incubated at $23^{\circ} \mathrm{C}$ for 48 to $72 \mathrm{~h}$. These stock cultures were frozen and stored at $-80^{\circ} \mathrm{C}$ until needed. Working cultures were prepared by inoculating thawed stock solution into MRS+R broth, incubating at $23^{\circ} \mathrm{C}$ for $72 \mathrm{~h}$, and then diluting to an optical density at 600 $\mathrm{nm}\left(\mathbf{O D}_{600}\right)$ of 1.3 , which had been determined to be the $\mathrm{OD}_{600}$ indicating a cell concentration of $10^{9} \mathrm{cfu} /$ mL (Supplemental Figure S1, https://doi.org/10.6084/ m9.figshare.14488896.v1). Enumeration of Pa. wasatchensis WDC04 was performed on MRS $+\mathrm{R}$ agar plates incubated at $23^{\circ} \mathrm{C}$ for $48 \mathrm{~h}$ in a Gaspak EZ system (Becton Dickinson).

Protective Cultures. Three $\mathrm{Gal}^{+} \mathrm{Lac}^{-}$protective cultures, Lacticaseibacillus (La.) paracasei UW4, Lactobacillus ( $L b$.) helveticus 7995 , and Pediococcus (Pd.) acidilactici $23 \mathrm{~F}$, were selected from the culture collections at Utah State University (Logan, UT) or Weber State University based on carbohydrate fermentation patterns from API50 CH panels (bioMérieux Inc.). Carbohydrate fermentation profiles for the protective cultures confirmed they all fermented glucose and galactose but not lactose. Lacticaseibacillus paracasei UW4 and $P d$. acidilactici $23 \mathrm{~F}$ were also able to utilize ribose and $N$-acetylglucosamine. Stock cultures were prepared by propagation in MRS broth at $30^{\circ} \mathrm{C}$ for 48 $\mathrm{h}$, frozen, and stored at $-80^{\circ} \mathrm{C}$ until needed. Working cultures were prepared from thawed stock culture and inoculated into MRS broth supplemented with $1 \%$ galactose (MRS+G; Sigma Aldrich Inc.), and incubated at $30^{\circ} \mathrm{C}$ for $10 \mathrm{~h}$ (previously determined to be the time when cell concentration reached $10^{9} \mathrm{cfu} / \mathrm{mL}$ ). Protective cultures were enumerated by plating on $\mathrm{MRS}+\mathrm{G}$ agar and incubating anaerobically at $30^{\circ} \mathrm{C}$ for $48 \mathrm{~h}$.

\section{Model Gas Production System}

Carbohydrate-restricted MRS (CR-MRS) broth was prepared as described in McMahon et al. (2020). Stock $10 \%$ (wt/vol) solutions of galactose and ribose were filter sterilized and stored at $22^{\circ} \mathrm{C}$. Test solutions 
containing $1 \%$ (wt/vol) sugars were prepared by adding ribose and galactose to CR-MRS broth at levels of $0.5 \%$ ribose $+0.5 \%$ galactose, $0.4 \%$ ribose $+0.6 \%$ galactose, $0.3 \%$ ribose $+0.7 \%$ galactose, $0.2 \%$ ribose $+0.8 \%$ galactose, and $0.1 \%$ ribose $+0.9 \%$ galactose. Half of the test tubes contained a Durham tube (Fisher Scientific) inverted onto a 6-cm-long capillary tube (Drummond Scientific Company; Figure 1) that was added before autoclaving. Test solutions (with and without Durham tubes) were inoculated with $\mathrm{Pa}$. wasatchensis WDC04 at $10^{1}, 10^{2}, 10^{3}, 10^{4}, 10^{5}, 10^{6}$, or $10^{7} \mathrm{cfu} / \mathrm{mL}$ on 3 different occasions. All of the test samples were incubated at $23^{\circ} \mathrm{C}$. Test tubes with Durham tubes were observed for gas production over a 21 -d period, and $\mathrm{OD}_{600}$ was measured in test tubes without a Durham tube. After

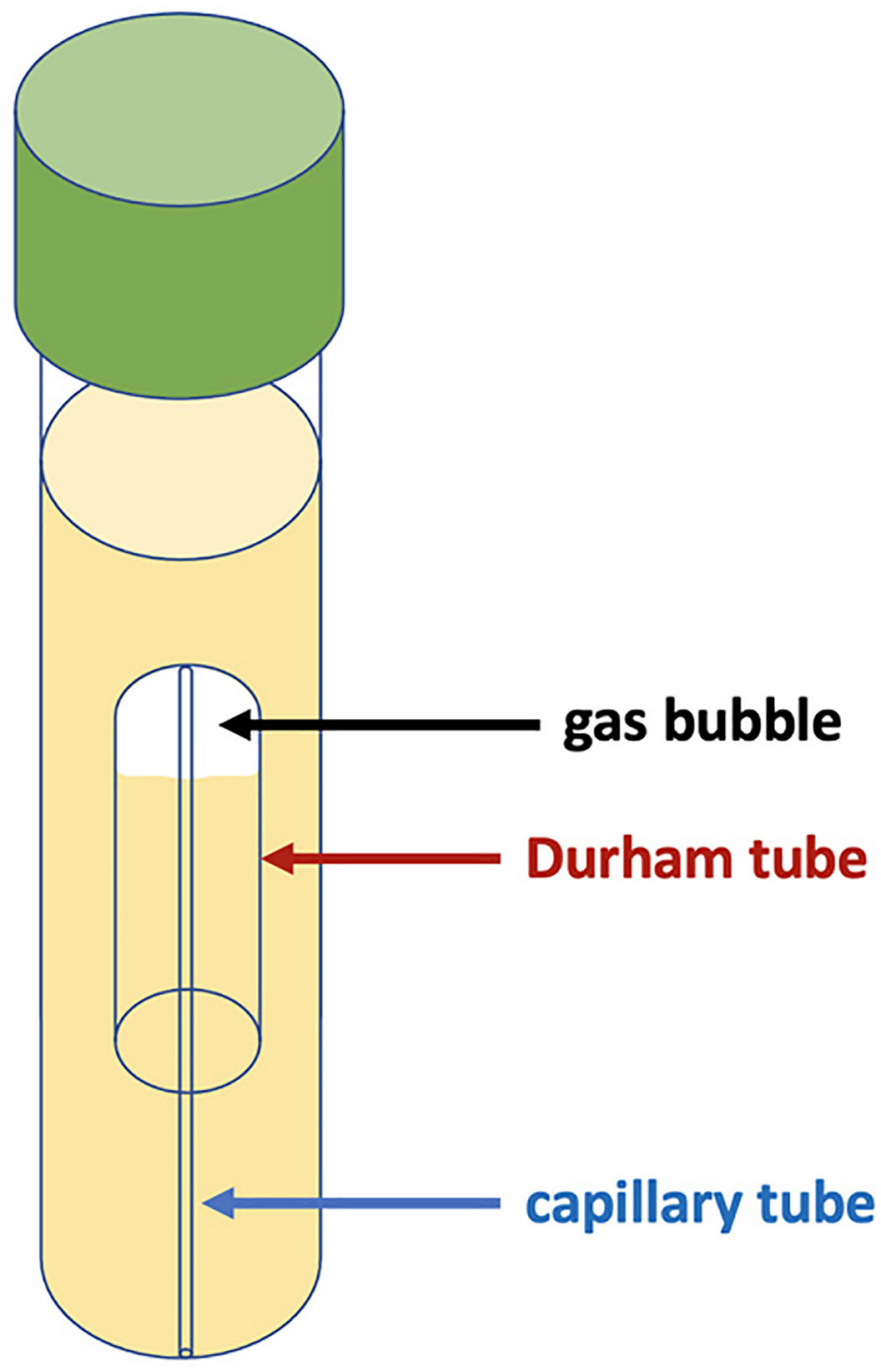

Figure 1. Test tube containing an inverted Durham tube resting on top of a 60 -mm-long capillary tube so as to increase volume beneath the Durham tube from which gas could be collected. this initial trial, the most consistent treatment combinations for producing a gas bubble were repeated an additional 5 times (on separate days). The combination of ribose + galactose concentration and Pa. wasatchensis WDC04 inoculum that produced a gas bubble 8 out of 8 times was selected as the GPT.

To explore the effects of protective cultures on gas production, each protective culture was added to the GPT at $10^{3}, 10^{4}, 10^{5}, 10^{6}$, or $10^{7} \mathrm{cfu} / \mathrm{mL}$. This was performed as biological replicates on 3 different days. Test tubes containing CR-MRS with $0.3 \%$ ribose and $0.7 \%$ galactose with and without Durham tubes were inoculated with $\mathrm{Pa}$. wasatchensis $\mathrm{WDC} 04$ and then with the protective culture; then growth $\left(\mathrm{OD}_{600}\right)$ and gas production were monitored daily. Plate counts were performed on $\mathrm{d} 4,8$, and 12 by serial dilution and plating on MRS+R and MRS $+\mathrm{G}$ agars. Control GPT tubes were inoculated with $P a$. wasatchensis WDC04 only.

\section{Galactose Analysis}

Galactose levels in the GPT tubes were measured enzymatically (LACGAR; Megazyme Ltd.) according to kit instructions. Samples were collected at 1, 4, 8, and $12 \mathrm{~d}$ and diluted 20 -fold before measurement.

\section{Statistical Analysis}

Differences in growth curves as a result of adding a protective culture were analyzed using a random-effects model. The remaining experiments were conducted using a nested factorial design. Statistical analysis was performed using Tukey HSD in JMP (version 14; SAS Institute Inc.).

\section{RESULTS AND DISCUSSION}

\section{Gas Production Test}

When gas bubbles in the Durham tubes did form, they were generally observed between d 8 and d 16 . In the initial trial, many of the treatments (with various levels of ribose, galactose, and $P a$. wasatchensis WDC04 inoculation) had gas formation observed in 1 or 2 of the broth samples but not in all 3 (Table 1). Gas production was more frequently observed when higher (i.e., $\geq 10^{5} \mathrm{cfu} / \mathrm{mL}$ ) numbers of $P a$. wasatchensis WDC04 were added, except at the lowest ribose level $(0.1 \%$ ribose, $0.9 \%$ galactose), in which no gas was observed at any inoculation level (Table 1). This was attributed to only minimal growth by $P a$. wasatchensis WDC04 with galactose, as previously shown (Ortakci et al., 2015; McMahon et al., 2020). If ribose concentration 
Table 1. Number of times gas production was observed in 3 independent replicate tubes of CR-MRS ${ }^{1}$ broth containing a total of $1 \%$ ribose and galactose at different ratios and with different inoculum levels of Paucilactobacillus wasatchensis WDC0 $4^{2}$

\begin{tabular}{|c|c|c|c|c|c|c|c|c|}
\hline \multicolumn{2}{|c|}{ Sugar ratio } & \multicolumn{7}{|c|}{ Inoculation level $(\mathrm{cfu} / \mathrm{mL})$} \\
\hline Ribose & Galactose & $10^{1}$ & $10^{2}$ & $10^{3}$ & $10^{4}$ & $10^{5}$ & $10^{6}$ & $10^{7}$ \\
\hline 50 & 50 & 0 & 1 & 2 & 0 & 2 & 2 & 2 \\
\hline 40 & 60 & 2 & 2 & 2 & 2 & 2 & 3 & 2 \\
\hline 30 & 70 & 0 & 2 & 2 & 2 & 3 & 3 & 2 \\
\hline 20 & 80 & 0 & 0 & 1 & 1 & 3 & 2 & 2 \\
\hline 10 & 90 & 0 & 0 & 0 & 0 & 0 & 0 & 0 \\
\hline
\end{tabular}

${ }^{1}$ Carbohydrate-restricted lactobacilli de Man, Rogosa, and Sharpe broth, with ribose and galactose as the only added sugars

${ }^{2}$ Incubation was performed at $23^{\circ} \mathrm{C}$.

was at least $0.2 \%$ (with $0.8 \%$ galactose), gas production was observed for inoculum levels of $\geq 10^{3} \mathrm{cfu} / \mathrm{mL}$. The inconsistency of observable gas production in the test medium is reflective of the sporadic nature of unwanted gas production in actual cheese during ripening. The most consistent gas production (i.e., gas present in all 3 replicates) occurred at inoculum levels of $10^{5}$ or $10^{6}$ $\mathrm{cfu} / \mathrm{mL}$ and ribose levels of 0.2 to $0.4 \%$ (along with 0.8 to $0.6 \%$ galactose, respectively; Table 1 ).

In the follow-up trial, the most rapid growth of $P a$. wasatchensis WDC04 occurred with an inoculum level of $10^{6} \mathrm{cfu} / \mathrm{mL}$ in CR-MRS containing $0.4 \%$ ribose and $0.6 \%$ galactose (reaching $\mathrm{OD}_{600}$ of 1.3 in $3 \mathrm{~d}$; Figure 2), but gas bubbles were not always produced (Table 2). The combinations using inoculum levels of $10^{5}$ or $10^{6}$ $\mathrm{cfu} / \mathrm{mL}$ in CR-MRS containing $0.3 \%$ ribose and $0.7 \%$ galactose both reached $\mathrm{OD}_{600}$ of 1.3 in 5 d. Growth was slowest (requiring $10 \mathrm{~d}$ to reach $\mathrm{OD}_{600}$ of 1.3 ) with the combination of a $10^{5} \mathrm{cfu} / \mathrm{mL}$ inoculum and sugar levels of $0.2 \%$ ribose and $0.8 \%$ galactose. The only combination that always (8 out of 8 times) showed gas production was an inoculum level of $10^{5} \mathrm{cfu} / \mathrm{mL}$ and sugar content of $0.3 \%$ ribose and $0.7 \%$ galactose. This CR-MRS broth formulation was designated as the gas production broth and, in combination with an inoculation of $10^{5} \mathrm{cfu} / \mathrm{mL}$ Pa. wasatchensis WDC04, was selected as GPT.

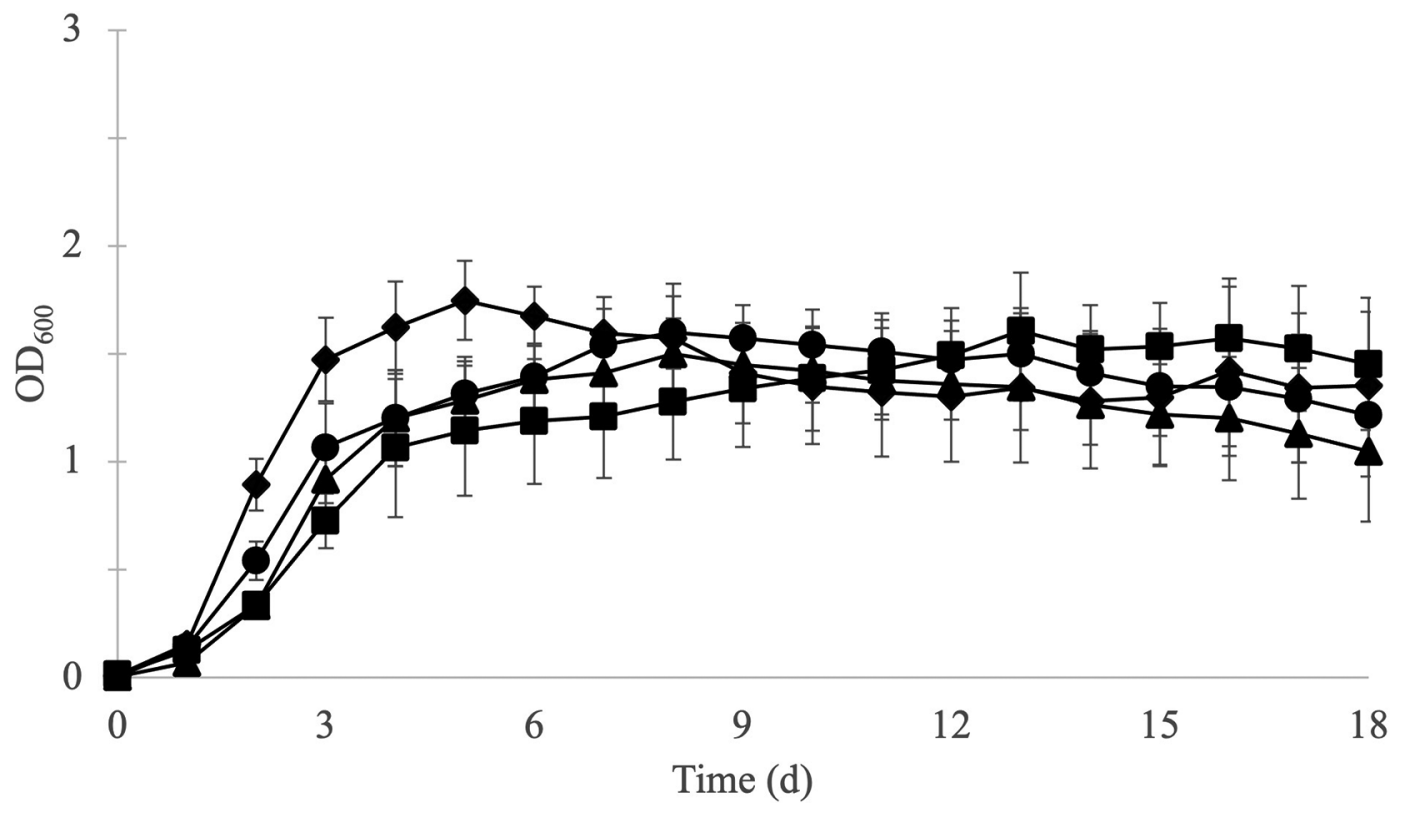

Figure 2. Growth at $23^{\circ} \mathrm{C}$ of Paucilactobacillus wasatchensis WDC04 inoculated at varying levels into carbohydrate-restricted de Man, Rogosa, and Sharpe broth containing 1\% sugar consisting of varying ratios of ribose:galactose, as follows: (ם) 20:80 ratio with 10 $0^{5}$ cfu/mL, $(\mathbf{\Lambda})$ $30: 70$ ratio with $10^{5} \mathrm{cfu} / \mathrm{mL},(\bullet) 30: 70$ ratio with $10^{6} \mathrm{cfu} / \mathrm{mL}$, and $(\bullet)$ 40:60 ratio with $10^{6} \mathrm{cfu} / \mathrm{mL}$ based on optical density at $600 \mathrm{~nm}\left(\mathrm{OD}_{600}\right)$. Data reported as the mean $\pm \mathrm{SE}$ of 5 independent replicates. 
Table 2. Time (d) during incubation at $23^{\circ} \mathrm{C}$ before gas production by Paucilactobacillus wasatchensis WDC04 was observed in carbohydrate-restricted de Man, Rogosa, and Sharpe broth formulations (5 independent replicates) that showed the most consistent results in preliminary trials (Table 1)

\begin{tabular}{lcccc}
\hline & \multicolumn{4}{c}{ Ribose:galactose (inoculum level, cfu/mL) } \\
\cline { 2 - 5 } Replicate & $20: 80\left(10^{5}\right)$ & $30: 70\left(10^{5}\right)$ & $30: 70\left(10^{6}\right)$ & $40: 60\left(10^{6}\right)$ \\
\hline 1 & -1 & 7 & 9 & 6 \\
2 & 16 & 6 & 6 & 8 \\
3 & 6 & 6 & 7 & 9 \\
4 & -7 & 7 & - & - \\
5 & - &
\end{tabular}

\section{Growth and Interaction of WDC04 and Protective Cultures in GPT}

When Pa. wasatchensis WDC04 was grown using the GPT, exponential growth was observed through 4-d incubation at $23^{\circ} \mathrm{C}$ and then slower growth over the next $4 \mathrm{~d}$ to an $\mathrm{OD} \sim 1.5$, followed by a slight decrease (Figure 3). Based on prior correlations of $\mathrm{OD}_{600}$, the cell numbers would be predicted to be $10^{9} \mathrm{cfu} / \mathrm{mL}$ (see Supplemental Figure S1). Gas bubbles were observed in the Durham tube starting on d 6 (Table 2) and at least by d 8 , when growth appeared to reach a plateau. This growth is fueled by ribose along with co-utilization of galactose (Ortakci et al., 2015a), and growth slows down as ribose is exhausted and the cell needs to use galactose for energy production (McMahon et al., 2020). To be used for energy production, galactose is converted into 6-P-gluconate, and then a molecule of $\mathrm{CO}_{2}$ is released to produce ribulose-5-P, which can then be metabolized through the pentose phosphate pathway.
When grown in the gas production broth (CR-MRS $+0.3 \%$ ribose $+0.7 \%$ galactose), the protective cultures all grew faster than $\mathrm{Pa}$. wasatchensis WDC04 and reached maximum $\mathrm{OD}_{600}(\sim 2.5)$ within 2 to $4 \mathrm{~d}$, depending on the initial inoculation level (Figure 4). Plate counting was performed every $4 \mathrm{~d}$, and by d 4 all the protective cultures had reached $10^{9} \mathrm{cfu} / \mathrm{mL}$. This level was maintained for La. paracasei UW4, but for $P d$. acidilactici $23 \mathrm{~F}$ and $L b$. helveticus 7995 the cell numbers declined to $\sim 10^{8} \mathrm{cfu} / \mathrm{mL}$ by d 12 (Figure 5 ).

When a protective culture was grown along with $P a$. wasatchensis WDC04 as part of the GPT, less growth of both bacteria occurred. Each protective culture was at consistently lower numbers at $\mathrm{d} 4$ when grown with $P a$. wasatchensis WDC04, regardless of the inoculum level used, and cell numbers reached only $\sim 10^{8} \mathrm{cfu} /$ $\mathrm{mL}$ (Figure 5). Having to compete for resources with the protective cultures also reduced the growth of $P a$. wasatchensis $\mathrm{WDC04}(P<0.05)$, which reached only $\sim 5 \times 10^{7} \mathrm{cfu} / \mathrm{mL}$, compared with $1 \times 10^{9} \mathrm{cfu} / \mathrm{mL}$ when grown on its own (Table 3 ).

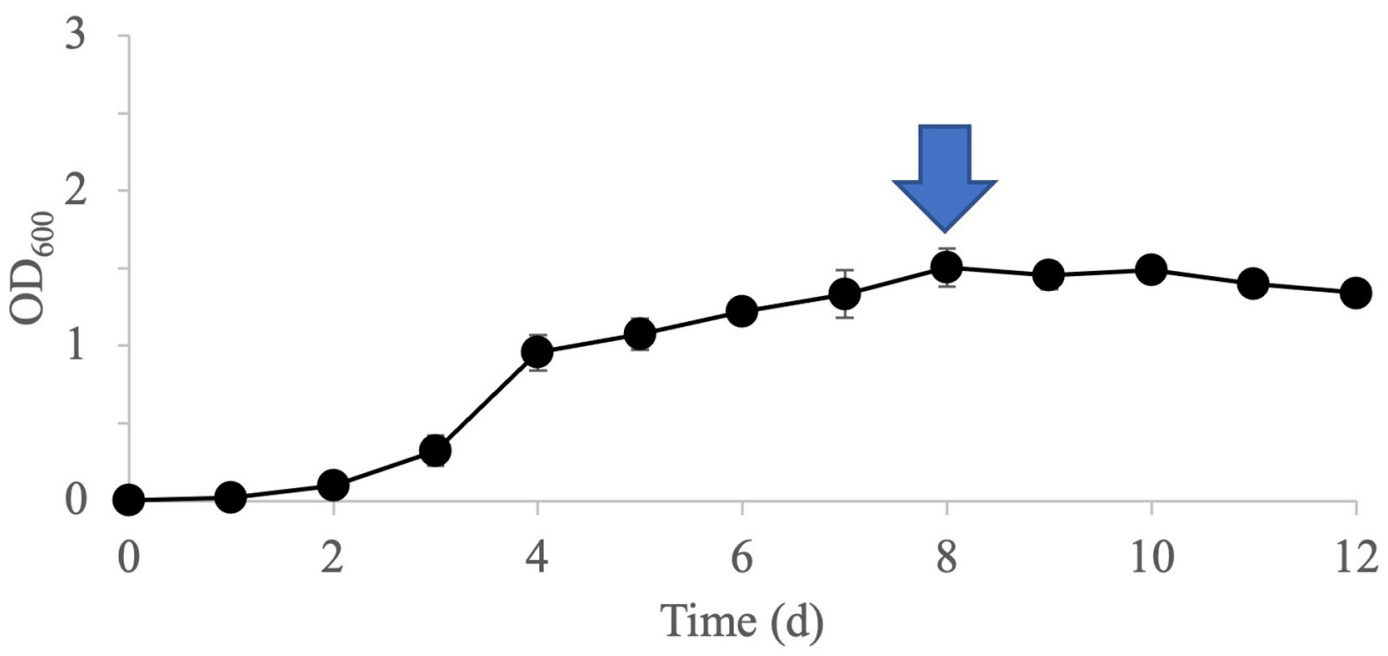

Figure 3. Growth at $23^{\circ} \mathrm{C}$ of Paucilactobacillus wasatchensis WDC04 when inoculated at $10^{5} \mathrm{cfu} / \mathrm{mL}$ into gas production broth (carbohydrate-restricted de Man, Rogosa, and Sharpe broth containing $0.3 \%$ ribose and $0.7 \%$ galactose) monitored by optical density at $600 \mathrm{~nm}\left(\mathrm{OD}_{600}\right)$, showing first observation of gas bubble (arrow). Data reported as the mean \pm SE of 3 independent replicates. 

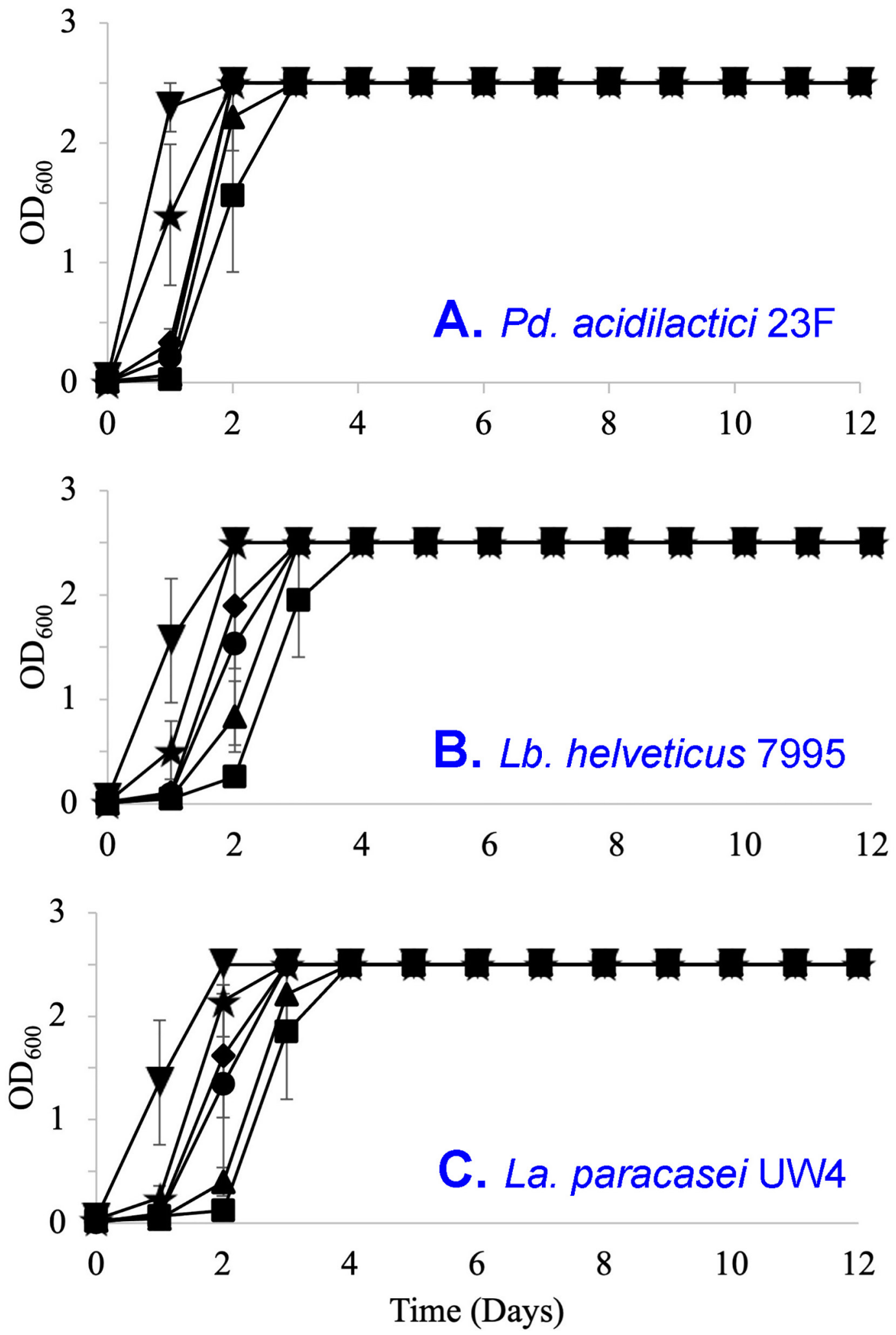

Figure 4. Growth measured daily using optical density at $600 \mathrm{~nm}\left(\mathrm{OD}_{600}\right)$ of protective cultures (A) Pediococcus acidilactici 23F, (B) Lactobacillus helveticus 7995, and (C) Lacticaseibacillus paracasei UW4 in gas production broth (carbohydrate-restricted de Man, Rogosa, and Sharpe broth containing $0.3 \%$ ribose and $0.7 \%$ galactose) at $23^{\circ} \mathrm{C}$ and inoculated at levels of $10^{5} \mathrm{cfu} / \mathrm{mL}$ on its own $(\bullet)$ or inoculated at $10^{3}(\mathbf{\square})$, $10^{4}(\mathbf{\Lambda}), 10^{5}(\diamond), 10^{6}(\star)$, or $10^{7}(\boldsymbol{\nabla}) \mathrm{cfu} / \mathrm{mL}$ along with $10^{5} \mathrm{cfu} / \mathrm{mL}$ of Paucilactobacillus wasatchensis WDC04. Data reported as the mean \pm $\mathrm{SE}$ of 3 independent replicates. 



Figure 5. Growth measured every $4 \mathrm{~d}$ using plate counting of protective cultures (A) Pediococcus acidilactici 23F, (B) Lactobacillus helveticus 7995, and (C) Lacticaseibacillus paracasei UW4 in gas production broth (carbohydrate-restricted de Man, Rogosa, and Sharpe broth containing $0.3 \%$ ribose and $0.7 \%$ galactose) at $23^{\circ} \mathrm{C}$ and inoculated at levels of $10^{5} \mathrm{cfu} / \mathrm{mL}$ on its own $(\bullet)$ or inoculated at $10^{3}(\boldsymbol{\square}), 10^{4}(\boldsymbol{\Delta}), 10^{5}(\bullet), 10^{6}$ $(\star)$, or $10^{7}(\boldsymbol{\nabla}) \mathrm{cfu} / \mathrm{mL}$ along with $10^{5} \mathrm{cfu} / \mathrm{mL}$ of Paucilactobacillus wasatchensis WDC04. Data reported as the mean $\pm \mathrm{SE}$ of 3 independent replicates. 
Table 3. Mean numbers (cfu/mL) of Paucilactobacillus wasatchensis WDC04 grown in carbohydrate-restricted de Man, Rogosa, and Sharpe broth containing $0.3 \%$ ribose and $0.7 \%$ lactose in the absence or presence of a protective culture during incubation over $12 \mathrm{~d}$ at $23^{\circ} \mathrm{C}$ from 3 independent replicates

\begin{tabular}{lcccc}
\hline & \multicolumn{4}{c}{ Incubation time } \\
\cline { 2 - 5 } Protective culture & $0 \mathrm{~d}$ & $4 \mathrm{~d}$ & $8 \mathrm{~d}$ & $12 \mathrm{~d}$ \\
\hline Control $^{1}$ & $1.5 \times 10^{5 \mathrm{a}}$ & $1.9 \times 10^{9 \mathrm{a}}$ & $3.2 \times 10^{9 \mathrm{a}}$ & $1.2 \times 10^{9 \mathrm{a}}$ \\
$23 \mathrm{~F}^{2}$ & $1.8 \times 10^{5 \mathrm{a}}$ & $1.5 \times 10^{8 \mathrm{c}}$ & $6.8 \times 10^{7 \mathrm{~b}}$ & $4.4 \times 10^{7 \mathrm{c}}$ \\
$\mathrm{UW}^{3}$ & $2.3 \times 10^{5 \mathrm{a}}$ & $2.8 \times 10^{8 \mathrm{bc}}$ & $6.0 \times 10^{7 \mathrm{~b}}$ & $5.2 \times 10^{7 \mathrm{bc}}$ \\
$7995^{4}$ & $1.8 \times 10^{5 \mathrm{a}}$ & $3.2 \times 10^{8 \mathrm{~b}}$ & $2.5 \times 10^{7 \mathrm{~b}}$ & $4.6 \times 10^{7 \mathrm{c}}$ \\
\hline
\end{tabular}

${ }^{a-c}$ Means in the same column with different letters were significantly different; $\alpha=0.05$.

${ }^{1}$ No protective culture added.

${ }^{2}$ Pediococcus acidilactici $23 \mathrm{~F}$.

${ }^{3}$ Lacticaseibacillus paracasei $\mathrm{UW} 4$.

${ }^{4}$ Lactobacillus helveticus 7995.

\section{Influence of Protective Cultures on Gas Production by Pa. wasatchensis WDC04}

When any of the protective cultures were added to the GPT, no gas production was observed, even at the lowest inoculum level $\left(10^{3} \mathrm{cfu} / \mathrm{mL}\right)$. Utilization of galactose by the protective cultures can reduce the growth rate of $P a$. wasatchensis so that less galactose is available to participate in exponential growth via coutilization with ribose, and it removes the availability of any hexoses that can result in $\mathrm{CO}_{2}$ production.

Adding any of the protective cultures significantly $(P<0.05)$ reduced the growth of $P a$. wasatchensis WDC0 4 by $\mathrm{d} 4$ and through $12 \mathrm{~d}$ of incubation (Table 3 ). Protective culture $P d$. acidilactici $23 \mathrm{~F}$ had the largest effect, with $P a$. wasatchensis WDC04 counts only reaching $1.5 \times 10^{8} \mathrm{cfu} / \mathrm{mL}$ by d 4 , compared with $1.9 \times$ $10^{9} \mathrm{cfu} / \mathrm{mL}$ when grown its own. Both $P d$. acidilactici

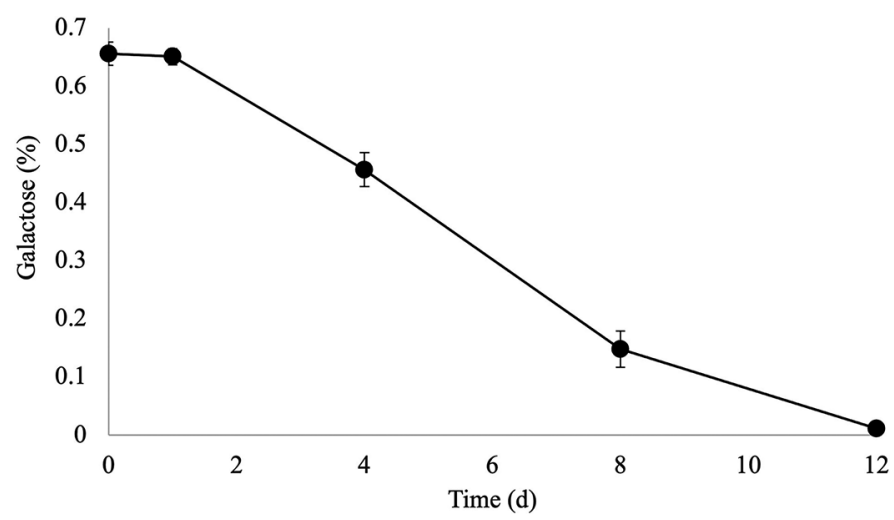

Figure 6. Galactose concentration in gas production broth (carbohydrate-restricted de Man, Rogosa, and Sharpe broth containing $0.3 \%$ ribose and $0.7 \%$ galactose) inoculated with $10^{5} \mathrm{cfu} / \mathrm{mL}$ Paucilactobacillus wasatchensis WDC04 and incubated at $23^{\circ} \mathrm{C}$. Data reported as the mean $\pm \mathrm{SE}$ of 3 independent replicates.
$23 \mathrm{~F}$ and La. paracasei UW4 have the ability to ferment ribose (as shown by API50 CH panels), and this could also contribute to lower growth of $P a$. wasatchensis WDC04 as well as depletion of galactose. In contrast, $L b$. helveticus 7995 cannot ferment ribose, and it had the least effect on growth of $\mathrm{Pa}$. wasatchensis WDC04 (Table 3).

In the GPT when Pa. wasatchensis WDC04 is the only bacteria (inoculated at $10^{5} \mathrm{cfu} / \mathrm{mL}$ ), the galactose level stayed at its initial mean $( \pm \mathrm{SE})$ level of $0.66 \%$ $( \pm 0.18 \%)$ for $1 \mathrm{~d}$, then steadily decreased to $0.15 \%$ by d 8 before tapering more slowly to $0.01 \%$ at d 12 (Figure 6). This period from d 1 to $\mathrm{d} 8$ corresponds with the time of exponential growth for $P a$. wasatchensis WDC04 (Figure 3) and, when no gas production was observed, supports the finding of Ortakci et al. (2015a) that galactose is co-metabolized with ribose when they are present together. Ribose is primarily utilized for ATP production via the pentose phosphate pathway, whereas galactose is directed toward biosynthesis of peptidoglycans and other cellular macromolecules (Ortakci et al., 2015a).

Once ribose is depleted, $P a$. wasatchensis must shuttle some galactose through the heterofermentative phosphoketolase pathway (which results in $\mathrm{CO}_{2}$ production) to produce ribulose-5-P that can then be used to generate energy. Galactose consumption was essentially linear between d 2 to 8 , by which time $P a$. wasatchensis WDC04 achieved maximum biomass, and ribose would have been depleted sometime before $\mathrm{d} 8$ (actual ribose levels were not measured). More gradual galactose utilization after d 8 likely reflects the need for maintaining energy in the cells. When any of the protective cultures were included in the GPT, galactose was depleted and completely consumed by d 4 (Figure 7), even with the lowest inoculum level of $10^{3} \mathrm{cfu} / \mathrm{mL}$. At the highest inoculum level $\left(10^{7} \mathrm{cfu} / \mathrm{mL}\right)$, galactose depletion was rapid, with about half consumed by $\mathrm{d} 1$. 



Figure 7. Galactose concentration in gas production broth (carbohydrate-restricted de Man, Rogosa, and Sharpe broth containing $0.3 \%$ ribose and $0.7 \%$ galactose) inoculated with adjunct cultures (A) Pediococcus acidilactici 23F, (B) Lactobacillus helveticus 7995 and (C) Lacticaseibacillus paracasei UW4 inoculated at $10^{5} \mathrm{cfu} / \mathrm{mL}(\bullet)$ or inoculated with $10^{5} \mathrm{cfu} / \mathrm{mL}$ Paucilactobacillus wasatchensis WDC04 and $10^{3}(\boldsymbol{\square}), 10^{4}(\boldsymbol{\Lambda}), 10^{5}$ $(\checkmark), 10^{6}(\star)$, or $10^{7}(\boldsymbol{\nabla}) \mathrm{cfu} / \mathrm{mL}$ of the adjunct culture and incubated at $23^{\circ} \mathrm{C}$. Data reported as the mean $\pm \mathrm{SE}$ of 3 independent replicates. 


\section{CONCLUSIONS}

Gas production by $P a$. wasatchensis WDC04 was consistently observed in Durham tubes in 6 to $8 \mathrm{~d}$ when using an inoculation level of $10^{5} \mathrm{cfu} / \mathrm{mL}$ in CR-MRS broth containing $0.3 \%$ ribose and $0.7 \%$ galactose as the only sugars and incubating at $23^{\circ} \mathrm{C}$. This combination of nutrients provided for growth of $P a$. wasatchensis WDC04 to $10^{9} \mathrm{cfu} / \mathrm{mL}$ based on co-utilization of ribose and galactose, with sufficient galactose remaining by d 8 to generate enough $\mathrm{CO}_{2}$ to create a gas bubble. When a faster-growing $\mathrm{Gal}^{+} \mathrm{Lac}^{-}$adjunct culture such as La. paracasei UW4, Lb. helveticus 7995, or Pd. acidilactici $23 \mathrm{~F}$ was included, growth of $P a$. wasatchensis WDC04 was impeded, and all the galactose was utilized while Pa. wasatchensis WDC04 was still in exponential growth. With no residual galactose that could be utilized after the ribose had been depleted, no $\mathrm{CO}_{2}$ was produced. This shows the potential for using a $\mathrm{Gal}^{+}$ $\mathrm{Lac}^{-}$adjunct culture in Cheddar cheese manufacture to prevent unwanted gas production and formation of cracks and slits.

\section{ACKNOWLEDGMENTS}

This research was funded by the BUILD Dairy program of the Western Dairy Center (Logan, UT), with financial support from Dairy West (Meridian, ID) and regional dairy processing companies. We thank the Aggie creamery staff (Logan, UT) for providing the pasteurized milk and assistance in cheesemaking. This research was also supported by the Utah Agricultural Experiment Station, Utah State University (Logan, UT), and approved as journal paper number 9438. R. $\mathrm{K}$. Thunell is employed by Vivolac Cultures Corp., who supplied the starter culture used in this study, and these cultures are non-proprietary and commercially available. The outcomes of this study have general application to all Lactococcus starter cultures used for manufacture of Cheddar cheese and none of the authors obtain any financial benefit from the study. The authors have not stated any other potential conflicts of interest.

\section{REFERENCES}

Bley, M. E., M. E. Johnson, and N. F. Olson. 1985. Factors affecting nonenzymatic browning of process cheese. J. Dairy Sci. 68:555561. https://doi.org/10.3168/jds.S0022-0302(85)80858-4.

Broadbent, J. R., K. Houck, M. E. Johnson, and C. J. Oberg. 2003. Influence of adjunct use and cheese microenvironment on nonstarter bacteria in reduced-fat Cheddar-type cheese. J. Dairy Sci. 86:2773-2782. https://doi.org/10.3168/jds.S0022-0302(03)73874 -0 .
Crow, V. L., T. Coolbear, P. K. Gopal, F. G. Martley, L. L. McKay, and $\mathrm{H}$. Riepe. 1995. The role of autolysis of lactic acid bacteria in the ripening of cheese. Int. Dairy J. 5:855-875. https://doi.org/10 .1016/0958-6946(95)00036-4.

Fox, P. F., P. L. H. McSweeney, and C. M. Lynch. 1998. Significance of non-starter lactic acid bacteria in Cheddar cheese. Aust. J. Dairy Technol. 53:83-89.

Hutkins, R. W., and C. Ponne. 1991. Lactose uptake driven by galactose efflux in Streptococcus thermophilus: Evidence for a galactoselactose antiporter. Appl. Environ. Microbiol. 57:941-944. https:// doi.org/10.1128/aem.57.4.941-944.1991.

McMahon, D. J., I. B. Bowen, I. Green, M. Domek, and C. J. Oberg. 2020. Growth and survival characteristics of Paucilactobacillus wasatchensis WDCO4. J. Dairy Sci. 103:8771-8781. https://doi .org/10.3168/jds.2020-18597.

McMahon, D. J., C. J. Oberg, M. A. Drake, N. Farkye, L. V. Moyes, M. R. Arnold, B. Ganesan, J. Steele, and J. R. Broadbent. 2014 Effect of sodium, potassium, magnesium, and calcium salt cations on $\mathrm{pH}$, proteolysis, organic acids, and microbial populations during storage of full-fat Cheddar cheese. J. Dairy Sci. 97:4780-4798. https://doi.org/10.3168/jds.2014-8071.

Michel, V., and F. G. Martley. 2001. Streptococcus thermophilus in Cheddar cheese production and fate of galactose. J. Dairy Res. 68:317-325. https://doi.org/10.1017/S0022029901004812.

Oberg, C. J., L. V. Moyes, M. J. Domek, C. F. Brothersen, and D. J. McMahon. 2011. Survival of probiotic adjunct cultures in cheese and challenges in their enumeration using selective media. J. Dairy Sci. 94:2220-2230. https://doi.org/10.3168/jds.2010-3934.

Oberg, C. J., T. S. Oberg, M. C. Culumber, F. Ortakci, J. R. Broadbent, and D. J. McMahon. 2016. Lactobacillus wasatchensis sp. nov., a non-starter lactic acid bacterium isolated from aged Cheddar cheese. Int. J. Syst. Evol. Microbiol. 66:158-164. https://doi .org/10.1099/ijsem.0.000689.

Ortakci, F., J. R. Broadbent, C. J. Oberg, and D. J. McMahon. 2015b. Late blowing of Cheddar cheese induced by accelerated ripening and ribose and galactose supplementation in presence of a novel obligatory heterofermentative nonstarter Lactobacillus wasatchensis. J. Dairy Sci. 98:7460-7472. https://doi.org/10.3168/jds.2015 $-9468$.

Ortakci, F., J. R. Broadbent, C. J. Oberg, and D. J. McMahon. 2015c. Growth and gas formation by Lactobacillus wasatchensis, a novel obligatory heterofermentative nonstarter lactic acid bacterium, in a Cheddar-style cheese made using a Streptococcus thermophilus starter. J. Dairy Sci. 98:7473-7482. https://doi.org/10.3168/jds $2015-9556$.

Ortakci, F., J. R. Broadbent, C. J. Oberg, and D. J. McMahon. 2015a. Growth and gas production of a novel obligatory heterofermentative Cheddar cheese nonstarter lactobacilli species on ribose and galactose. J. Dairy Sci. 98:3645-3654. https://doi.org/10.3168/jds .2014-9293.

Tinson, W., M. F. Ratcliff, A. J. Hillier, and G. R. Jago. 1982. Metabolism of Streptococcus thermophilus. 3. Influence on the level of bacterial metabolites in Cheddar cheese. Aust. J. Dairy Technol. $37: 17-21$.

Wilkinson, M. G. 1993. Acceleration of cheese ripening. Pages 523-555 in Cheese: Chemistry, Physics and Microbiology, Vol. 1. General Aspects. 2nd ed. P. F. Fox, ed. Chapman and Hall.

\section{ORCIDS}

Craig J. Oberg @ https://orcid.org/0000-0001-6033-7033

Randall K. Thunell ๑ https://orcid.org/0000-0003-0192-2237

Donald J. McMahon 주 https://orcid.org/0000-0002-7923-8542 